\title{
Caracterização tecnológica da argila plástica de Pântano Grande, RS
}

\section{(Technical characterization of plastic clay from Pantano Grande, RS, Brazil)}

\author{
R. T. da Cruz, C. P. Bergmann, S. R. Bragança \\ Laboratório de Materiais Cerâmicos, DEMAT, EE, UFRGS, R. Osvaldo Aranha 99/705, \\ Centro, Porto Alegre RS 90035-190 \\ saulorb@ufrgs.br
}

\begin{abstract}
Resumo
A região de Pântano Grande, RS, é conhecida pela qualidade de seus caulins. Nesta região, incluindo-se as cercanias das cidades de Gravataí e Viamão, encontra-se uma argila plástica de cor de queima clara, mas com característica refratária. Ressalva-se a importância desta argila, pela dificuldade de se obter argilas plásticas a distâncias convenientes para indústria cerâmica. Neste trabalho, foi realizada a caracterização tecnológica desta argila. As propriedades de queima foram avaliadas para a faixa de temperatura de $1200{ }^{\circ} \mathrm{C}$ a $1400{ }^{\circ} \mathrm{C}$, incluindo-se uma mistura com uma argila refratária e queima a $1300{ }^{\circ} \mathrm{C}$. Após, investigou-se o comportamento de gresificação por meio de misturas com fundentes sódicos, potássicos e cálcicos, analisando-se também a resistência mecânica à flexão. Deste modo, obteve-se a completa caracterização da referida argila, destacando-se o potencial de aplicação da mesma.
\end{abstract}

Palavras-chave: matérias-primas, argila plástica, caracterização tecnológica.

Abstract

The region of Pantano Grande, RS, Brazil, is known by the quality of its kaolins. In this region, including the nearby of the cities of Gravatai and Viamão, there is a plastic clay of clear firing color, but with refractory characteristic. The use of this clay is very attractive, since it is difficulty to get plastic clays at convenient distances for the ceramic industry. In this work, it was carried out the technological characterization of this clay. The firing properties have been evaluated for the temperature range $1200{ }^{\circ} \mathrm{C}-1400{ }^{\circ} \mathrm{C}$, including a mixture with a refractory clay and fired at $1300^{\circ} \mathrm{C}$. It was investigated the firing behavior of mixtures with $\mathrm{Na}$, $\mathrm{K}$, and $\mathrm{Ca}$ fluxes, including the analysis of the mechanical strength. In this way, it was performed a complete characterization of the related clay, and highlighted its potential of application.

Keywords: raw-materials, plastic clay, technical characterization.

\section{INTRODUÇÃO}

Importantes reservas de caulim são encontradas no estado do Rio Grande do Sul, as quais fornecem matériasprimas de qualidade às indústrias cerâmicas. Entre estas, incluiu-se as cerâmicas locais e de Santa Catarina. As reservas são estimadas em um total de 20 milhões de toneladas [1]. As principais jazidas e as mais exploradas são da região de Pântano Grande. Em estudos geológicos já realizados, atribuiu-se a origem do caulim dessa região como "fruto da alteração intempérica de rochas anortosíticas, nas zonas de contato com granitóides, gerando assembléias minerais secundárias à base de caolinita e haloisita" [2,3]. Em determinadas ocorrências, pode-se encontrar maiores concentrações de matéria orgânica, conferindo um maior teor de plasticidade a determinadas argilas. Embora geneticamente iguais aos caulins das principais jazidas de Pantano Grande, essas argilas apresentam algumas particularidades, típicas do local onde são encontradas. Ao mesmo tempo em que as argilas em questão possuem maior plasticidade que caulins, elas apresentam principalmente caolinita e algum quartzo, tratando-se, portanto, de argilas de elevada refratariedade. Devido às características pouco comuns dessas argilas, surgiu o propósito deste trabalho de analisar este material, estudando suas propriedades por meio de análises composicionais e mineralógicas, distribuição granulométrica, propriedades térmicas e caracterização tecnológica no intervalo de queima 1200-1400 ${ }^{\circ} \mathrm{C}$. Em consequência das características refratárias dessa argila, testou-se uma mistura com um caulim utilizado comercialmente na indústria de refratários e, paralelamente, algumas formulações com fundentes, realizando-se uma investigação inicial sobre as características de gresificação da argila.

\section{MATERIAIS E MÉTODOS}

A composição química dos materiais utilizados neste trabalho é mostrada na Tabela I, sendo esta análise realizada por fluorescência de raios X, Shimatzu WDS. Para a rocha fundente, o percentual de óxido de lítio foi 
Tabela I - Composição química das matérias-primas.

[Table I - Raw materials chemical composition.]

\begin{tabular}{ccccccc}
\hline $\begin{array}{c}\text { Componentes } \\
(\%)\end{array}$ & Caulim & $\begin{array}{c}\text { Argila } \\
\mathrm{RE}\end{array}$ & $\begin{array}{c}\text { Rocha } \\
\text { fundente }\end{array}$ & $\begin{array}{c}\text { Wollas- } \\
\text { tonita }\end{array}$ & $\begin{array}{c}\text { Feldspato } \\
\text { potássico }\end{array}$ & Vidro \\
\hline $\mathrm{SiO}_{2}$ & 50,79 & 56,40 & 77,03 & 51,40 & 68,70 & 70,28 \\
$\mathrm{Al}_{2} \mathrm{O}_{3}$ & 36,50 & 25,72 & 15,26 & 0,66 & 17,10 & 2,21 \\
$\mathrm{Fe}_{2} \mathrm{O}_{3}$ & 0,77 & 0,86 & 0,12 & 0,22 & 0,33 & 0,08 \\
$\mathrm{MgO}$ & 0,28 & 0,42 & 0,01 & 0,50 & - & 1,76 \\
$\mathrm{CaO}$ & 0,01 & 0,12 & 0,26 & 46,10 & 0,65 & 10,36 \\
$\mathrm{Na} 2$ & 0,06 & 0,05 & 3,23 & - & 2,90 & 13,24 \\
$\mathrm{~K}_{2} \mathrm{O}$ & 1,48 & 0,61 & 1,21 & 0,32 & 9,80 & 0,75 \\
$\mathrm{Li}_{2} \mathrm{O}$ & - & - & 2,18 & - & - & - \\
$\mathrm{TiO}_{2}$ & 0,06 & 1,05 & 0,02 & 0,02 & 0,05 & 0,15 \\
$\mathrm{Perda} \mathrm{fogo}(\%)$ & 10,05 & 14,76 & 0,63 & 0,65 & 0,5 & - \\
\hline
\end{tabular}

Tabela II - Formulações propostas.

[Table II - Specimen compositions.]

\begin{tabular}{|c|c|}
\hline Formulação & \\
\hline A & $80 \%$ argila $\mathrm{RE}+20 \%$ rocha fundente \\
\hline B & $\begin{array}{c}80 \% \text { argila RE }+10 \% \text { feldspato }+10 \% \\
\text { wollastonita }\end{array}$ \\
\hline $\mathrm{C}$ & $\begin{array}{c}80 \% \text { argila } \mathrm{RE}+10 \% \text { feldspato }+10 \% \\
\text { vidro }\end{array}$ \\
\hline $\mathrm{D}$ & $\begin{array}{l}80 \% \text { argila } \mathrm{RE}+10 \% \text { feldspato }+5 \% \\
\quad \text { wollastonita }+5 \% \text { vidro }\end{array}$ \\
\hline Refratário & $20 \%$ argila $\mathrm{RE}+80 \%$ caulim \\
\hline
\end{tabular}

atribuído indiretamente a partir da análise petrográfica e análise por absorção atômica [4]. A composição química apresentada na forma de óxidos, na argila estudada, denominada RE, apresenta baixos teores dos óxidos de maior poder de fundência como os alcalinos e alcalinos terrosos.

A argila RE é proveniente da região de Pântano Grande, RS. O caulim é utilizado pela empresa Inducel Ltda. de Urussanga, SC, para produção de refratários. A wollastonita é um mineral sintético e foi fornecida pela empresa Nyco Minerals. O feldspato foi fornecido pela empresa Mineração Sartor em Pedras Grandes, SC. A rocha fundente foi fornecida pela Colorminas S.A.. O vidro é proveniente da limpeza e moagem de embalagens transparentes, produzidas com vidro sodo-cálcico. Estes fundentes foram escolhidos de modo a testar a reatividade da argila RE com diferentes tipos e teores de óxidos fundentes, como $\mathrm{Na}_{2} \mathrm{O}$ (vidro), $\mathrm{K}_{2} \mathrm{O}$ (feldspato potássico), $\mathrm{Li}_{2} \mathrm{O}$ (rocha fundente) e $\mathrm{CaO}$ (wollastonita).

As formulações propostas no estudo de gresificação e de produção de um material refratário são mostradas na Tabela II.

A Tabela III apresenta o teor de óxidos fundentes nas diferentes formulações. Procurou-se utilizar os fundentes com granulometria aproximada (Tabela IV), medida em granulômetro a laser Cilas 1180 .

As massas granuladas foram compactadas, utilizandose uma prensa hidráulica com estampos metálicos, com as dimensões $20 \times 60 \mathrm{~mm}^{2}$, com altura de aproximadamente $7 \mathrm{~mm}$, em regime uniaxial de simples efeito. Os corpos cerâmicos foram secos em temperatura ambiente por $24 \mathrm{~h}$ e após este período em estufa a $110^{\circ} \mathrm{C}$ por mais $24 \mathrm{~h}$. Foram queimados em fornos elétricos, tipo mufla, variando-se a temperatura, conforme a formulação investigada. Foram determinadas as propriedades tecnológicas como absorção de água, densidade de Arquimedes e resistência mecânica por ruptura à flexão 4 pontos. $\mathrm{O}$ índice de plasticidade foi realizado pelo método de Atterberg [5].

A análise das fases mineralógicas na argila RE foi realizada por difração de raios X (Philips X-Pert).

Tabela III - Óxidos fundentes nas formulações para estudo de gresificação.

[Table III - Flux oxides in bodies for firing behavior study.]

\begin{tabular}{ccccccccc}
\hline Formulação / \% & $\mathrm{Li}_{2} \mathrm{O}$ & $\mathrm{K}_{2} \mathrm{O}$ & $\mathrm{CaO}$ & $\mathrm{Na}_{2} \mathrm{O}$ & $\mathrm{MgO}$ & $\Sigma$ total & $\Sigma \mathrm{R}_{2} \mathrm{O}$ & $\Sigma \mathrm{RO}$ \\
\hline $\mathrm{A}$ & 0,44 & 0,73 & 0,15 & 0,69 & 0,34 & 2,34 & 1,85 & 0,49 \\
$\mathrm{~B}$ & 0,0 & 1,50 & 4,77 & 0,33 & 0,36 & 6,97 & 1,83 & 5,13 \\
$\mathrm{C}$ & 0,0 & 1,54 & 1,20 & 1,65 & 0,51 & 4,91 & 3,20 & 1,71 \\
$\mathrm{D}$ & 0,0 & 1,52 & 2,98 & 0,99 & 0,45 & 5,94 & 2,51 & 3,43 \\
\hline
\end{tabular}


Tabela IV - Granulometria dos fundentes.

[Table IV - Fluxes particle size distribution.]

\begin{tabular}{lccc}
\hline \multicolumn{4}{c}{ Distribuição Granulométrica da matéria-prima $(\mu \mathrm{m})$} \\
\hline Amostra & $10 \%<$ & $90 \%<$ & Média \\
Feldspato & 2,03 & 51,49 & 22,5 \\
Rocha fundente & 1,28 & 37,68 & 15,11 \\
Vidro & 2,35 & 34,28 & 17,98 \\
Wollastonita & 1,13 & 29,55 & 12,78 \\
\hline
\end{tabular}

\section{RESULTADOS E DISCUSSÃO}

Na primeira parte deste estudo, apresenta-se a avaliação da argila RE e o comportamento frente à queima dos corposde-prova prensados. Na parte final, é mostrada a avaliação da referida argila em misturas com os fundentes em termos de comportamento frente gresificação.

\section{Caracterização da argila $R E$}

A análise das fases mineralógicas detectadas via difração de raios X mostrou caolinita, ilita e quartzo como principais fases na argila RE, sendo mostrada na Fig. 1. A distribuição granulométrica mostra se tratar de uma argila bastante fina

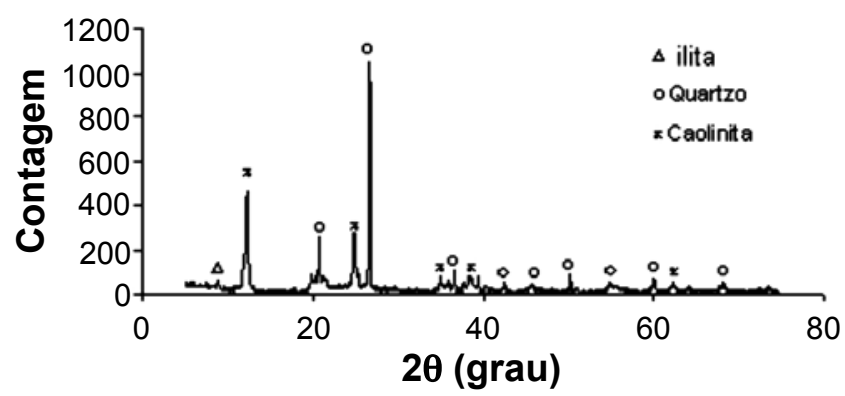

Figura 1: análise mineralógica da argila RE.

[Figure 1: mineralogical analysis of RE clay.]

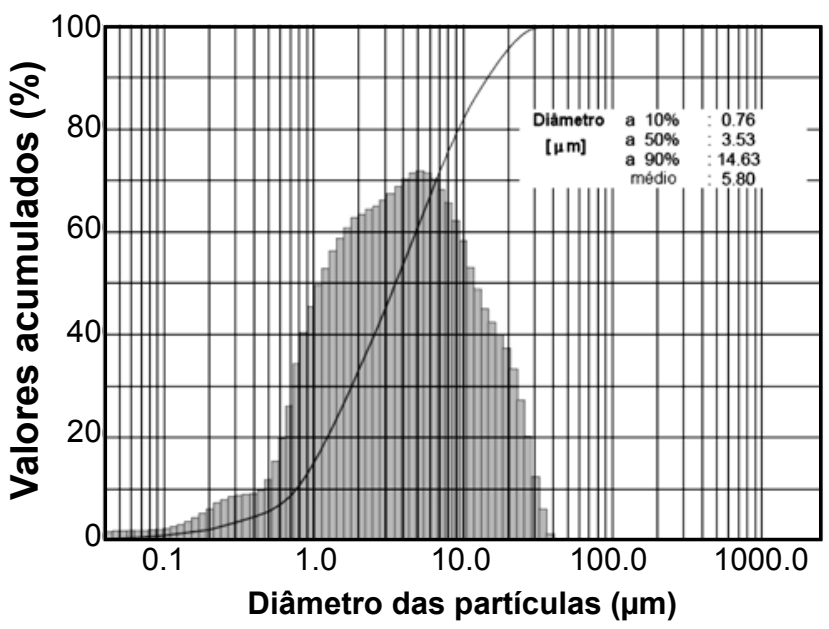

Figura 2: Distribuição granulométrica da argila RE. [Figure 2: Particle size distribution of RE clay.]

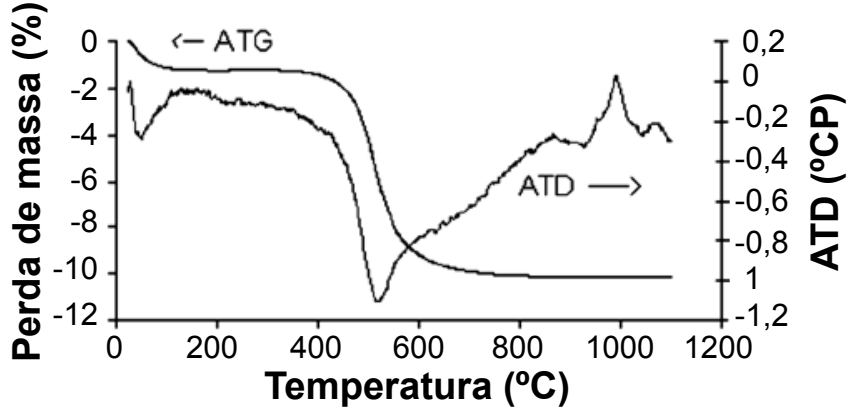

Figura 3: Análise termogravimétrica (ATG) e análise térmica diferencial (ATD).

[Figure 3: Thermogravimetric (ATG) and thermal differential analysis (ATD) curves.]

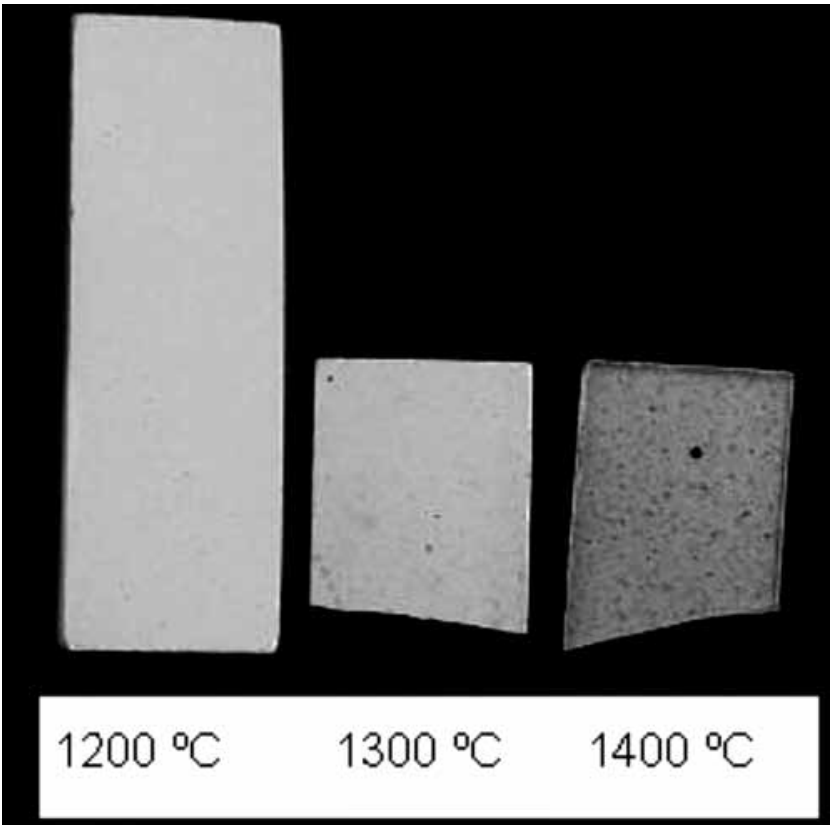

Figura 4: Cor de queima em atmosfera oxidante da argila RE. [Figure 4: Firing color in oxidizing atmosphere of RE clay.]

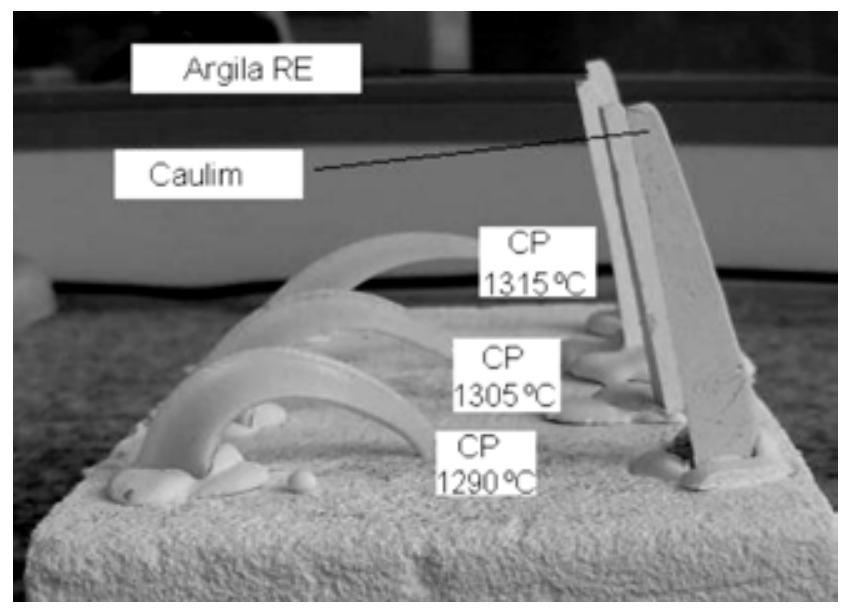

Figura 5: Ensaio de refratariedade simples por comparação de cones pirométrico equivalentes.

[Figure 5: Pyrometric cone equivalent comparative analysis.] 
Tabela V - Caracterização tecnológica da formulação $100 \%$ argila RE e da formulação argila RE (20\%) e caulim (80\%). [Table V - Technical characterization of RE clay body and RE clay (20\%) + kaolin (80\%) body.]

\begin{tabular}{ccccccc}
\hline $\begin{array}{c}\text { Formulação e } \\
\text { T de queima }\end{array}$ & $\begin{array}{c}\text { Retração } \\
(\%)\end{array}$ & $\begin{array}{c}\text { Perda } \\
\text { Massa } \\
(\%)\end{array}$ & $\begin{array}{c}\text { Abs. de } \\
\text { água }(\%)\end{array}$ & $\begin{array}{c}\text { Porosidade } \\
\text { Aparente }(\%)\end{array}$ & $\begin{array}{c}\text { Dens. } \\
\text { arquim. } \\
\left(\mathrm{g} / \mathrm{cm}^{3}\right)\end{array}$ & $\begin{array}{c}\text { Res. } \\
\text { Mec. } \\
(\mathrm{MPa})\end{array}$ \\
\hline 100\% RE: $1200\left({ }^{\circ} \mathrm{C}\right)$ & 5,87 & 8,71 & 8,55 & 17,92 & 2,10 & 26,16 \\
100\% RE: $1300\left({ }^{\circ} \mathrm{C}\right)$ & 7,48 & 9,99 & 4,39 & 10,17 & 2,32 & 31,70 \\
$20 \%$ RE + 80\%Caulim: $1300\left({ }^{\circ} \mathrm{C}\right)$ & 6,86 & 10,06 & 7,73 & 16,87 & 2,18 & 23,53 \\
$100 \%$ RE: $1400\left({ }^{\circ} \mathrm{C}\right)$ & 8,67 & 10,07 & 1,67 & 4,01 & 2,41 & 44,84 \\
\hline
\end{tabular}

(Fig. 2), com aproximadamente $15 \%$ da massa menor que 1 $\mu \mathrm{m}$. Há uma concentração do quartzo na granolometria mais grosseira (observado em lupa eletrônica), mas mesmo assim esta fase está presente em granulação fina, o que é desejável para materiais gresificados. Destaca-se na Fig. 2 que 100\% do material é menor que $40 \mu \mathrm{m}$ e $90 \%$ menor que $14,6 \mu \mathrm{m}$. Essas características fazem que essa argila seja razoavelmente plástica, obtendo o índice de plasticidade de $24,5 \%$, o que se pode considerar um bom valor para produção de pisos de queima branca, comparando-se com outros tipos de argilas [6, 7]. Além disso, ela possui elevado teor de matéria orgânica, expresso pela perda ao fogo na Tabela I.

A Fig. 3 mostra por meio da análise térmica um comportamento típico de uma argila caolinítica, confirmando a análise feita por difração de raios X (Fig. 1). A argila apresenta boa definição dos picos de desidroxilação e formação da metacaolinita $\left(\sim 550^{\circ} \mathrm{C}\right)$, formação de espinélio $\left(\sim 900{ }^{\circ} \mathrm{C}\right)$ e mulitização $\left(>1000^{\circ} \mathrm{C}\right)$.

A cor de queima apresentada na Fig. 4 mostra que a argila RE tem queima clara para $1200{ }^{\circ} \mathrm{C}$ e $1300{ }^{\circ} \mathrm{C}$. Porém, nesta última temperatura aparecem algumas manchas, sendo estas muito intensificadas na temperatura de $1400{ }^{\circ} \mathrm{C}$. Nesta temperatura, as peças estão gresificadas, com a fase vítrea propiciando maior translucidez. Assim, a presença dos compostos colorantes, que mesmo em pequena proporção (expresso como óxidos na Tabela $\mathrm{I}$ : $\mathrm{Fe}_{2} \mathrm{O}_{3}+\mathrm{TiO}_{2}<2 \%$ ) escurecem a coloração da peça. Soma-se a este efeito a presença de maior quantidade de fase vítrea, relacionada com a menor absorção de água das peças em $1400{ }^{\circ} \mathrm{C}$ (Tabela V).

As propriedades de queima da argila RE são apresentadas na Tabela V. Pode-se notar que essa argila apresenta boas características refratárias, podendo ser utilizada para este propósito. Ela apresenta uma boa porosidade $\sim 10 \%$ para queima em $1300{ }^{\circ} \mathrm{C}$, mesmo sem a utilização de chamota; sendo, portanto, fácil o ajuste da retração e porosidade pela adição desse material [8,9]. A argila RE melhora a plasticidade na batelada de conformação, característica intrínseca desta argila, mas mantém a refratariedade elevada, como se pode ver na Tabela $\mathrm{V}$, na formulação argila $\mathrm{RE}+$ caulim. Isto propicia um benefício na utilização dessa argila em uma batelada, uma vez que caulins em geral possuem baixa plasticidade. A Fig. 5 mostra que a argila RE apresenta refratariedade superior ao cone de queima referente à temperatura de $1300{ }^{\circ} \mathrm{C}$. Portanto, pode-se empregar essa formulação para produção de refratários silicoaluminosos da classe SA-3 [10].

\section{Caracterização da argila RE adicionada de fundentes}

Os diferentes fundentes testados apresentaram uma boa reação com a argila RE, apresentando potencial para fabricação de diversos produtos como grês, louças e faianças, cerâmicas sanitárias e porcelanas. Ressalva-se, no entanto, que a referida argila apresenta potencial, mas dependendo do produto, estudos complementares são necessários, em termos de alvura, características reológicas, deformação sobre queima e evolução microestrutural na queima $[11,12]$. No quesito porosidade em relação à temperatura de queima, notase, por exemplo, que na temperatura de $1200{ }^{\circ} \mathrm{C}$, foi possível reduzir a absorção de água de 8,5\% (Tabela V) para índices bastante menores, de 0,77\% a 3,22\% (Tabela VI). Em 1240 ${ }^{\circ} \mathrm{C}$ as formulações B, C e D mostram absorção de água menor que $0,5 \%$. A formulação $\mathrm{A}$ foi a menos fundente, mesmo possuindo óxido de lítio, mas notadamente apresenta menor teor de óxidos $\mathrm{R}_{2} \mathrm{O}$ e $\mathrm{RO}$, quase a metade das outras. Face a isto, seria interessante estudar rochas mais ricas em minerais fundentes de lítio. Em $1220{ }^{\circ} \mathrm{C}$ os fundentes mais enérgicos foram os das formulações $\mathrm{B}$ e $\mathrm{D}$, os quais apresentam maior concentração de óxidos $\mathrm{R}_{2} \mathrm{O}$ e $\mathrm{RO}$ em relação a $\mathrm{B}$ (Tabela III). Já em $1200{ }^{\circ} \mathrm{C}$ a formulação D com a mistura de vidro e wollastonita foi mais fundente que as formulações somente com wollastonita ou vidro, B e C, respectivamente. Neste caso, a explicação pode estar em uma melhor homogeneidade da microestrutura advindas da utilização de um número maior de matérias-primas, ou seja, uma melhor distribuição dos óxidos fundentes, propiciando um melhor desenvolvimento das reações necessárias à formação da fase vítrea. Mecanismo semelhante foi proposto no estudo da formação de mulita [13] .

Tabela VI - Absorção de água em relação a temperatura de queima.

[Table VI - Water absorption in function of firing temperature.]

Formulação /

Abs. de Água $\quad 1180{ }^{\circ} \mathrm{C} \quad 1200{ }^{\circ} \mathrm{C} \quad 1220{ }^{\circ} \mathrm{C} \quad 1240{ }^{\circ} \mathrm{C}$ (\%)

\begin{tabular}{lllll} 
A & 3,67 & 3,22 & 1,76 & 1,45 \\
B & 3,82 & 1,90 & 0,28 & 0,24 \\
C & 2,68 & 2,03 & 0,85 & 0,26 \\
D & 2,23 & 0,77 & 0,11 & 0,19 \\
\hline
\end{tabular}


Tabela VII - Caracterização tecnológica para temperatura de queima de $1240{ }^{\circ} \mathrm{C}$. [Table VII - Technical characterization for firing temperature $1240^{\circ} \mathrm{C}$.]

\begin{tabular}{cccccccc}
\hline Formulação & $\begin{array}{c}\text { Dens. Seco } \\
\left(\mathrm{g} / \mathrm{cm}^{3}\right)\end{array}$ & $\begin{array}{c}\text { Retração } \\
(\%)\end{array}$ & $\begin{array}{c}\text { Perda } \\
\text { Massa } \\
(\%)\end{array}$ & $\begin{array}{c}\text { abs. água } \\
(\%)\end{array}$ & $\begin{array}{c}\text { Poros. } \\
\text { Aparente } \\
(\%)\end{array}$ & $\begin{array}{c}\text { Dens. } \\
\text { arquim. } \\
\left(\mathrm{g} / \mathrm{cm}^{3}\right)\end{array}$ & $\begin{array}{c}\text { Res. Mec. } \\
(\mathrm{MPa})\end{array}$ \\
\hline $\mathrm{A}$ & 1,97 & 8,02 & 8,40 & 1,45 & 3,33 & 2,39 & 45,90 \\
$\mathrm{~B}$ & 1,93 & 5,84 & 8,53 & 0,24 & 0,37 & 2,22 & 42,94 \\
$\mathrm{C}$ & 1,94 & 7,62 & 8,41 & 0,26 & 0,39 & 2,33 & 44,53 \\
$\mathrm{D}$ & 1,93 & 6,11 & 8,54 & 0,19 & 0,27 & 2,24 & 41,92 \\
\hline
\end{tabular}

Os fundentes utilizados nas formulações estudadas atuaram de maneira a promover a formação de fase vítrea em menor temperatura, em conseqüência da presença de óxidos alcalinos e alcalinos terrosos em vidros silicosos, os quais modificam as propriedades da fase vítrea, de modo a acelerar a densificação por fluxo viscoso [14]. Os eutéticos formados são conhecidos nos diagramas $\mathrm{Na}_{2} \mathrm{O}-\mathrm{SiO}_{2}-$ $\mathrm{Al}_{2} \mathrm{O}_{3}, \mathrm{~K}_{2} \mathrm{O}-\mathrm{SiO}_{2}-\mathrm{Al}_{2} \mathrm{O}_{3}$ e $\mathrm{CaO}-\mathrm{Na}_{2} \mathrm{O}-\mathrm{SiO}_{2}$, apresentando temperaturas menores que $1000{ }^{\circ} \mathrm{C}$ [15].

A caracterização completa das peças é mostrada na Tabela VII para a temperatura de queima de $1240{ }^{\circ} \mathrm{C}$. Os dados mostrados (Tabela VII) revelam que a argila RE apresenta bom potencial para produção de diversos produtos cerâmicos, alcançando bons valores de retração e resistência mecânica.

\section{CONCLUSÕES}

A argila estudada apresentou características interessantes para utilização na indústria cerâmica, com a particularidade de ser refratária, ter cor de queima branca e possuir boa plasticidade. Este estudo mostrou que essa argila é adequada para produtos refratários, uma vez que apresenta principalmente caolinita em sua composição mineral. Pode ser igualmente utilizada para produtos gresificados, já que possui boa reatividade com os fundentes testados.

\section{AGRADECIMENTOS}

À FAPERGS pelo apoio financeiro.

\section{REFERÊNCIAS}

[1] Departamento Nacional de Pesquisa Mineral - DNPM, Anuário Mineral Brasileiro, Brasília, DF (1991).

[2] A. Tedesco (1990), em F. Larroyd, Geologia $e$ caracterização tecnológica dos principais depósitos de caolim do estado do Rio Grande do Sul: ênfase a utilização na indústria do papel, Diss. Mestrado, Universidade Federal do Rio Grande do Sul, Porto Alegre, RS (1996) 4.

[3] D. Schenatto (1992), em F. Larroyd, Geologia $e$ caracterização tecnológica dos principais depósitos de caolim do estado do Rio Grande do Sul: ênfase a utilização na indústria do papel, Diss. Mestrado Universidade Federal do Rio Grande do Sul, Porto Alegre, RS (1996) 4.

[4] H. C. M. Lengler, Controle da porosidade em fases vitreas formadas pela ação de fundentes em cerâmicas gresificadas, Tese Dr., Universidade Federal do Rio Grande do Sul, Porto Alegre, RS (2006) 45.

[5] Associação Brasileira de Normas Técnicas ABNT-NBR 7180, Determinação do limite de plasticidade (1988).

[6] A. Barba, V. Beltrán, C. Felíu, J. Garcia, F. Ginés, E. Sánchez, V. Sanz, Materias primas para la fabricación de soportes de baldosas cerámicas, $2^{\mathrm{a}} \mathrm{Ed}$., Instituto de Tecnología Cerámica, Castellón, Espanha (2002) 224.

[7] C. M. F. Vieira, H. F. Sales, S. N. Monteiro, Cerâmica 50 , 315 (2004) 239-246.

[8] S. R. Bragança, C. P. Bergmann, Materiais refratários e abrasivos, em: G. Isaia, Ed., "Materiais de construção civil e princípios de ciência e engenharia de materiais", Vol. 1, Ibracon, S. Paulo, SP (2007) 620.

[9] G. L. Chavez, W. D. Johns, Appl. Clay Sci. 9 (1995) 407-424.

[10] Associação Brasileira de Normas Técnicas ABNTNBR 10237: Materiais refratários - Classificação (2001).

[11] E. Sanchez , M. J. Orts, J. García-Ten, V. Cantavella, Ceram. Ind. 6, 5 (2001) 15-22.

[12] G. P. Souza, E. Rambaldi, A. Tucci, L. Esposito, W. E. Lee, J. Am. Ceram. Soc. 87, 10 (2004) 1959-1966. [13] W. E. Lee, Y. Iqbal, J. Eur. Ceram. Soc. 21 (2001) 25832586

[14] J. M. F. Navarro, El Vidrio, CSIC, Madrid, Espanha (1991) 99.

[15] J. F. Shairer, J. Am. Ceram. Soc. 40, 7 (1957) 215-235. (Rec.06/12/2010, Ver. 04/04/2011, Ac. 05/04/2011) 